\title{
Hydatid Cyst of Breast: A Case Report
}

\author{
Alam $F^{1}$, Goel RG ${ }^{2}$
}

\begin{abstract}
Hydatid cyst is a zoonotic disease which occurs due to infectivity with larval stage of Echinococcus granulosus. The disease is chronic and cysts can be lodged in different organs. It has cosmopolitan distribution and impact health and economical challenges for many countries throughout the world. The location of the disease is mostly in the liver and lungs. Hydatid disease of breast is extremely rare. A case report of 24 year female with the diagnosis of the hydatid breast is described in detail. The patient presented with painless lump in the upper inner quadrant of right breast of two months duration. History of trauma, pus discharge, itching, weight loss, fever or hormonal therapy were absent. The patient was diagnosed preoperatively as cysticercosis right breast by fine needle aspiration cytology based on the laboratory results conducted outside the hospital. However, histopathology confirmed the diagnosis of hydatid breast. It is the second diagnosed case in Nepal. Therefore, accurate information on the distribution of the disease is first step for the control and prevention. Only few reports are published in the literature about breast hydatid cyst.
\end{abstract}

Thus, we want to emphasize the importance of keeping hydatid disease in differential diagnosis of cystic breast lesions, particularly in endemic region, where the disease could mimic fibroadenoma, phyllodes tumors, chronic abscesses.

Keywords: Breast, echinococcus, hydatid cyst.

\section{CASE REPORT}

A 24 year old female referred to Nepalgunj Medical College Teaching Hospital with a history of painless lump in her right breast of two months duration. There was no history of trauma, pus discharge, itching, weight loss, fever or hormonal therapy. There was no history of breast cancer in the family. Fine Needle Aspiration from her right breast was done in another laboratory with the diagnosis of cysticercosis of right breast. Her physical examination revealed a $5 \times 4 \mathrm{~cm}$ mass in the upper inner quadrant of her right breast. The mass was firm, non-tender, mobile with a clearly defined margin and overlying skin was normal. The left breast was normal. Both the nipples were normal and she had no axillary or supraclavicular lymphadenopathy. There was no mass in the abdomen. A postero-anterior view x-ray of the chest, showed no abnormality. All the routine blood tests were within normal limits.

The lump was removed surgically and an excisional biopsy specimen of the lump was received in pathology department for histopathological examination. Two separate tissue pieces were received in the same container, one was a solid tissue piece and the other was a pearly white cystic tissue piece (Fig.1.A). The solid tissue piece measured $4 \mathrm{~cm}$ in its maximum dimension with a firm graywhite cut surface. The other tissue

1. Dr. Fahad Alam

2. Prof. R. G. Goel

\section{Address of correspondence:}

Dr. Fahad Alam

Department of Pathology

Nepalgunj Medical College Teaching Hospital

Kohalpur, Banke, Nepal

E-mail: fahadalam14@gmail.com piece was pearly white semitranslucent with shiny inner surface giving it a boiled egg albumin like appearance, measuring $6 \mathrm{~cm}$ in length and was unilocular. Microscopically, the solid tissue showed breast lobules with mild round cell infiltrates here and there. At one edge there was a dense infiltrate consisting of round cells, many eosinophils and some neutrophils and at the free border of the section there were several protoscolices of larva of Echinococcus granulosus and in some of the scoleces, hooklets were clearly visible (Fig.1.B). Sections from the membranous tissue show classical laminated wall of the cyst (Fig.1.C) as well as the germinal layer from which several brood capsules containing protoscolices are arising (Fig.1.D). After diagnosing it as a hydatid cyst of right breast, we requested for the FNA slides where she was diagnosed as cysticercosis right breast and when meticulously examining the slides under the microscope, the aspirates showed hooklets of the parasite (Fig.1.F).

In our case the patient was discharged on her $3^{\text {rd }}$ postoperative day and she has not come for follow up yet.

\section{DISCUSSION}

According to Jarbou SM et $\mathrm{al}^{1}, 60 \%$ of the cysts are found in the liver, $30 \%$ in lungs, $2.5 \%$ in kidneys, $2.5 \%$ in heart and pericardium, $2 \%$ in bone, $1.5 \%$ in spleen, $1 \%$ in muscle and $0.5 \%$ in brain ${ }^{1}$. Hydatid disease of breast accounts for only $0.27 \%$ of all cases ${ }^{1}$.In a study by Echenique EM et al. on 405 patients of hydatid disease, rare presentation forms were encountered in 69 patients, however there was not a single case of hydatid disease of breast in that study, thereby showing extreme rareness of this presentation ${ }^{2}$. Upto 1994 only 54 hydatid cysts of the breast had been reported in the literature ${ }^{3}$. 


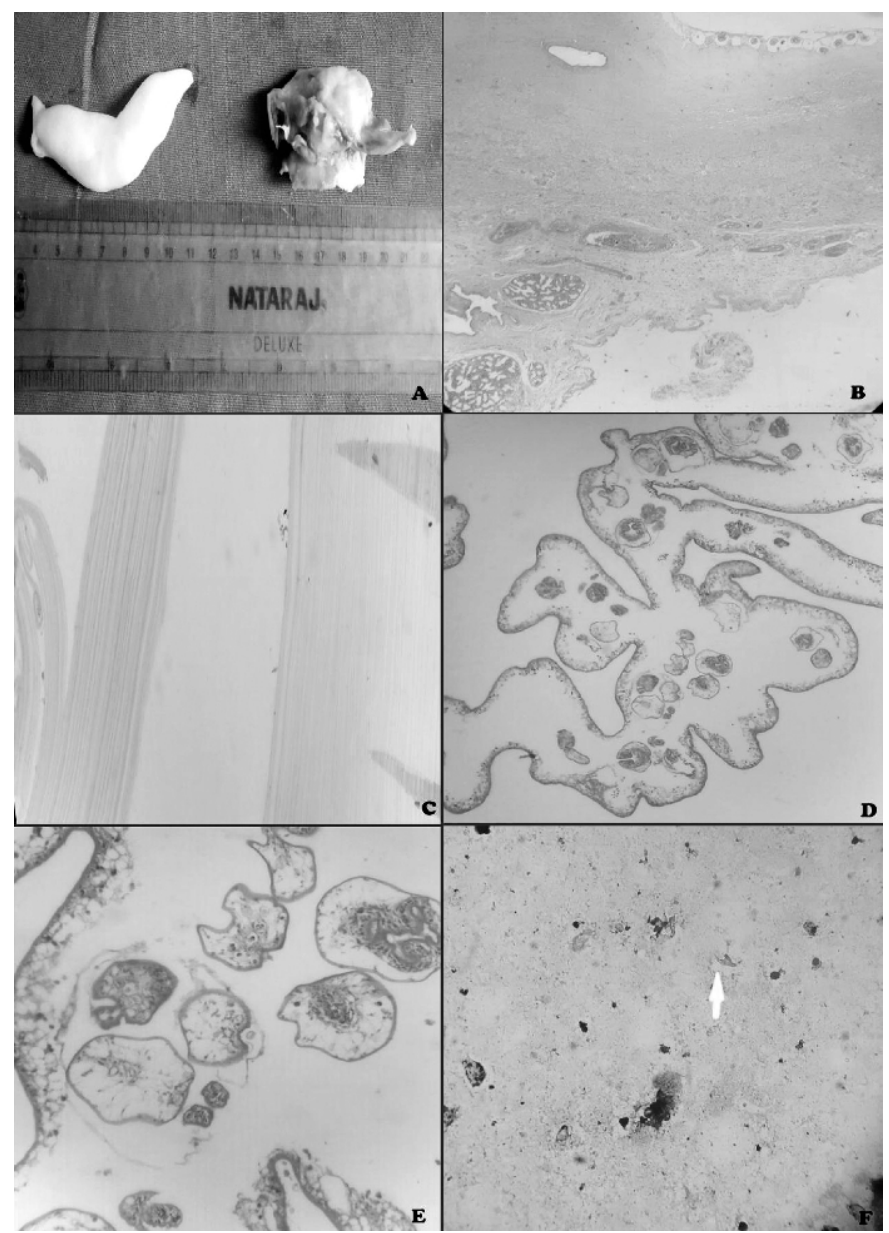

Figure 1.

A: Gross photograph of cystic tissue piece (left) and solid tissue piece (right)

B. Scanner view showing breast parenchyma and protoscolices (H \& E x 4)

C. Classical laminated wall of the cyst (H \& E x 4)

D. Germinal layer from which several brood capsules containing protoscolices are seen (H \& E x 4)

E. High power view of the brood capsules (H \& E x 10)

F. FNA of the right breast showing hooklet of parasite (Giemsa x 40)

Echinococcosis is caused by the larval tapeworm of the genus Echinococcus granulosus, Echinococcus multilocularis and Echinococcus oligarthrus. Echinococcus granulosus, the common cause of hydatid disease is found throughout the world, but it is particularly common in sheep and cattle raising countries. The primary host is the dog which passes gravid proglottids in the faeces, which on rupture release eggs that are subsequently swallowed by the intermediate hosts ${ }^{4}$. Typically the patient presents with painless breast lump, which increases slowly in size without regional lymph node involvement. It might mimic fibroadenoma, phyllodes tumor, chronic abscesses or even carcinoma ${ }^{1}$. Laboratory diagnosis requires microscopic identification of scolices or hooklets ${ }^{1}$. In our case the diagnosis of breast hydatid cyst was confimed by histopathological examination.

Breast can be the only site or part of disseminated hydatidosis. It generally affects woman of 30 to 50 years, although wider age range (20 to 74 ) has been reported. Pre-operative diagnosis can be made by fine needle aspiration cytology where hooklets or laminated membrane can be seen ${ }^{5}$.

The largest series of 20 hydatid cyst of the breast was reported in Tunisia ${ }^{3}$. There are stray reports of hydatid cysts of the breast from the Indian subcontinent ${ }^{6}$. From Nepal there was one case of breast hydatid cyst diagnosed by histopathological examination by Sah S et al. ${ }^{6}$ and this is probably the second diagnosed case of hydatid cyst of breast in Nepal.

\section{CONCLUSION}

Hydatid cyst should be considered in the differential diagnosis of breast lumps especially for those living in endemic areas.

\section{REFERENCES}

1. Jarbou SM, Salaita WM, Khasawneh MA. Isolated hydatid cyst of breast: A case report. JRMS 2007;14(1):64-65.

2. Gupta S, Verma DK, Prikshit, Kumar R. A rare presentation of hydatid disease:Breast lump. Journal of Case Reports 2014;4(2):33-35.

3. H. Uncu, S.Erekul. Hydatid cyst of the breast. Acta chir belg 2007;107:570-571.

4. Mirdha BR, Biswas A. Echinococcosis: presenting as palpable lump of breast. Indian J Chest Dis Allied Sci 2001;43:239-41.

5. Sagin HB, Kiroglu Y, Aksoy F. Hydatid cyst of breast diagnosed by fine needle aspiration biopsy; a case report. Acta Cytol 1994;38:965-67.

6. Sah SP, Agarwal CS, Khan IR, Rani S. Hydatid cyst presenting as a breast lump. Southeast Asian J Trop Med Public Health 2000;31(1):185-86. 